*Corresponding author: email joganro@csa.upv.es ; +34 963877120

\title{
Potentiometric Thick-film sensors for measuring the pH of concrete
}

\author{
J.M. Gandía-Romero ${ }^{1,2, *}$, I. Campos ${ }^{4}$, M. Valcuende ${ }^{2}$, E. García-Breijo ${ }^{3}$, M.D. Marcos ${ }^{1}$, J. Payá ${ }^{6}$, J. Soto ${ }^{1,5}$. \\ ${ }^{1}$ Research Center for Molecular Recognition and Technological Development (IDM), Universitat Politècnica de València, Camino \\ de vera s/n, 46022 Valencia, Spain. \\ ${ }^{2}$ Department of Architectural Constructions, Universitat Politècnica de València, Camino de vera s/n, 46022 Valencia, Spain. \\ ${ }^{3}$ Department of Electronic Engineering. Universitat Politècnica de València, Camino de vera s/n, 46022 Valencia, Spain. \\ ${ }^{4}$ Queen Mary University of London. Mile End Road, London E1 4NS \\ ${ }^{5}$ Department of Chemistry. Universitat Politècnica de València, Camino de vera s/n, 46022 Valencia, Spain. \\ ${ }^{6}$ Concrete Science and Technology Institute (ICITECH), Universitat Politècnica de València, Edificio 4N, Camino de Vera s/n \\ 46022 Valencia, Spain
}

\begin{abstract}
Concrete carbonation is one of the main triggers of the corrosion process and hence of the premature deterioration of concrete reinforcements. In order to monitor and control the carbonation process, a potentiometric sensor using thick-film technology was developed. This paper includes the results of the research carried out to characterise the $\mathrm{pH}$ sensor, including the materials, response time, sensitivity, detection limit, reproducibility, reversibility and the study of chloride interference. The sensors have been studied in pore solutions and concrete specimens. The study shows that the thick-film sensor has a potentiometric response to variations in $\mathrm{pH}$ and is capable of providing continuous, real-time information on the progress of the carbonation front.
\end{abstract}

Keywords: carbonatation; concrete; sensor; potentiometry; $\mathrm{pH}$; thick-film

\section{Introduction}

In reinforced concrete structures, one of the most frequent causes of pathology and possibly the one that has the greatest economic transcendence is reinforcement corrosion [1]. One of the basic mechanisms responsible for destroying the passivating oxide layer of steel bars is the reduction of alkalinity. $\mathrm{CO}_{2}$ may 
penetrate through the porous network of the concrete and react with calcium hydroxide and with the calcium silicate hydrates. The $\mathrm{CO}_{2}$ action occurs even when its concentration in the air is low. When $\mathrm{Ca}(\mathrm{OH})_{2}$ and the calcium silicate hydrates (C-S-H) react to transform into calcium carbonate, there is a decrease in the hydroxide concentration in the pore water and the concrete $\mathrm{pH}$ falls below 9 , destroying the passivating oxide layer and initiating the reinforcement corrosion if the thermodynamic conditions are favourable [2-5]. The major issue that arises with the tests that are commonly used to assess the concrete carbonation is that they are destructive tests [6], resulting in a deterioration of the analysed element. The most common test involves using an indicator solution containing phenolphthalein which allows the $\mathrm{pH}$ to be determined in a range of 8-9.5, at which point the phenolphthalein becomes colourless. However, it does not allow the $\mathrm{pH}$ of partially carbonated areas to be determined $[7,8]$. Less common techniques that require both specific equipment and specialized personnel are thermogravimetric analysis and X-ray diffraction [9-11]. Therefore, the development of non-invasive systems, such as the use of sensors, would greatly facilitate the control of such processes. This way, some parameters related to the durability of reinforced concrete structures can be monitored continuously and any necessary interventions may be foreseen, significantly reducing repair costs in the construction sector. Furthermore, in case interventions are needed, the sensors allow a non-destructive method of monitoring the effectiveness of the repair [12]. Although recent examples of parameter monitoring related to durability with the use of sensors in real structures exist [12-14], these systems are underdeveloped and can usually cause stability problems in the long-term.

Sensors are devices that are capable of transforming physical or chemical information from their environment into a signal that can later be processed. Electrochemical sensors are amongst the most widely used devices, one of these being the potentiometric sensor. Its operating principle is based on its potential change with regards to a reference electrode when no current flows through. This potential change is due to the chemical activity of sensed ion.

Sensor implementation for measuring $\mathrm{pH}$ in concrete structures is unusual. Optical sensors $[15,16]$ have proven to give good results, although they require complex equipment and may present durability problems in the medium- to long-term. Electrochemical sensors have also been implemented, with MMO (MetalMetal-Oxide) potentiometric sensors being the most common in concrete. The electrochemical response of these sensors depends on the Metal $(\mathrm{M})$ - Metal Oxide $\left(\mathrm{M}_{\mathrm{x}} \mathrm{O}_{\mathrm{y}}\right)$ reaction. Ti//rO $\mathrm{Ir}_{\mathrm{x}}[17]$ and $\mathrm{Ir} / \mathrm{IrO} \mathrm{I}_{2}[18,19]$ have also been used as $\mathrm{pH}$ sensors. However, the potential of $\mathrm{Ti}$ in alkaline solution is not stable, and the 
relationship between potential and $\mathrm{pH}$ is not linear [20]. Potentiometric $\mathrm{pH}$ sensors are electrodes that are usually made by anodizing a bar or metal surface and can show durability problems mainly due to oxide diffusion or the loss of activity. A good alternative are sensors manufactured using microelectronic technology called thick-film screen printing. Screen-printing technology is a printing technique which consists of using a rubber palette to apply inks with different characteristics through a display on the surface of a substrate. The main advantage and thus the application interest of these sensors over others is that they are robust, low-cost, and allow the addition of multiple sensors in one single piece of reduced size. Moreover, this technology is one of the most suitable for use in industrial production due to the possibility of using commercially available resistive pastes. On the other hand, vitreous matrices retain oxides, improving their durability and reducing the usual problems of diffusion of the oxides used in the sensors. Although thick-film sensors have been used in other industrial sectors (such as automotive, energy or medical), they are already beginning to be used in the structural field to measure deformations $[21,22]$, although no references have been found related to the durability of concrete. Metal oxide electrodes are most suitable to be manufactured by thick-film technology as many metal oxides can be used to measure $\mathrm{pH}$ [23-25]. Of these oxides, those based on the platinum group metals are most commonly used, particularly the oxides of iridium, platinum and ruthenium. Koncki and Mascini [26] obtained the best results with ruthenium dioxide. Other tested metal oxide electrodes had less sensitivity $\left(\mathrm{PdO}\right.$ and $\mathrm{TiO}_{2}$ ), or worse reproducibility (especially $\mathrm{TiO}_{2}$ ). The $\mathrm{PtO}_{2}$ electrodes showed high sensitivity (over $50 \mathrm{mV} / \mathrm{pH}$ ) in acidic solutions and had reproducible results but they also exhibited longer response time (around half an hour). In several studies, ruthenium oxide was employed as a $\mathrm{pH}$ sensor in an aqueous environment, showing a potentiometric Nernstian response to $\mathrm{pH}$ changes [23-29]; this means that there was a change in electrode potential of approximately $59 \mathrm{mV} / \mathrm{pH}$ at ambient temperature $\left(25{ }^{\circ} \mathrm{C}\right)$. According to Mihell and Atkinson [28] the response of this sensor to changes in $\mathrm{pH}$ was quite fast. However, there was a slower response in the alkaline medium.

Due to the fact that these sensors (with electrodes of different metal oxides) are effective in determining the $\mathrm{pH}$ in a liquid environment, the possibilities of using them in a solid environment, such as concrete, can also be explored. Therefore, the aim of this study was to examine the response of a thick-film $\mathrm{pH}$ electrode embedded in concrete. Three different metallic oxide types were used, measuring first their response in a 
liquid environment, which simulates the porous solution of concrete, and afterwards in concrete itself. The possibility of incorporating different electrodes in the same support allows us to determine the $\mathrm{pH}$ at different depths simultaneously, and therefore, know the speed of progression of the carbonation front of concrete.

\section{Experimental}

The study of potentiometric $\mathrm{pH}$ sensors manufactured by thick-film technology was divided in two stages. First, the behaviour was analysed in a liquid environment, simulating the porous solution of concrete. The study was done with three different metallic systems: $\mathrm{Ag}_{2} \mathrm{O}$ (Type 1), $\mathrm{TiO}_{2}$ (Type 2) and $\mathrm{RuO}_{2}$ (Type 3), using commercial resistive pastes for this purpose. In the second phase, the behaviour in concrete specimens was characterised, using only the manufactured sensors with the resistive paste that gave the best electrochemical response in the solution studies.

\subsection{Electrode fabrication}

The studied electrodes were screen printed onto $96 \%$ alumina substrate (CeramTec) with an area of $28 \mathrm{~mm} \mathrm{x}$ $58 \mathrm{~mm}$ and a thickness of $0.64 \mathrm{~mm}$, through successive layer deposition. An economical design of each sensor type permitted the simultaneous fabrication of nine electrodes on a single substrate, as shown in Fig. 1. Three screens were used, corresponding to the conductive layer (working as a conductor of the signal), the active layer and the protective layer. A layer of conductive material made of Ag/Pd (HERAEUS C1214D) was deposited over the alumina substrate to form the tracks and the electric connections and it was later fired in a box oven for $60 \mathrm{~min}$, with a heating rate of $33^{\circ} \mathrm{C} / \mathrm{min}$, a peak of $850^{\circ} \mathrm{C}$ for $10 \mathrm{~min}$ and a cooling rate of $33^{\circ} \mathrm{C} / \mathrm{min}$. Afterwards, the resistive paste was screen printed (the three types of pastes of the series R8900 from HERAEUS were analysed) and the sensor was exposed to a new thermal treatment in order to remove the organic vehicle of the ink, as well as adding, adhering and stabilizing the metallic oxide over the driving track. The firing was in a box oven for $30 \mathrm{~min}$, with a heating rate of $60^{\circ} \mathrm{C} / \mathrm{min}$, a peak of $700^{\circ} \mathrm{C}$ for $10 \mathrm{~min}$ and a cooling rate of $60^{\circ} \mathrm{C} / \mathrm{min}$. The burning protocol becomes essential because if the burning temperature is not appropriate, a thin vitrified layer can form, preventing contact with the active oxide [30,23]. The windows of the sensor electrodes were $2 \times 5 \mathrm{~mm}\left(10 \mathrm{~mm}^{2}\right)$. Lastly, the dielectric layer was added (GWENT D50706P3), coating the different conductor tracks but not the active surface of the oxide sensor or the 
electric connection area. Gwent D50706P3 is a blue coloured screen printable polymer dielectric which it has to be dried to $80^{\circ} \mathrm{C}$ for $30 \mathrm{~min}$ in a box oven. In all steps the burning processes have been made in controlled atmosphere of air.

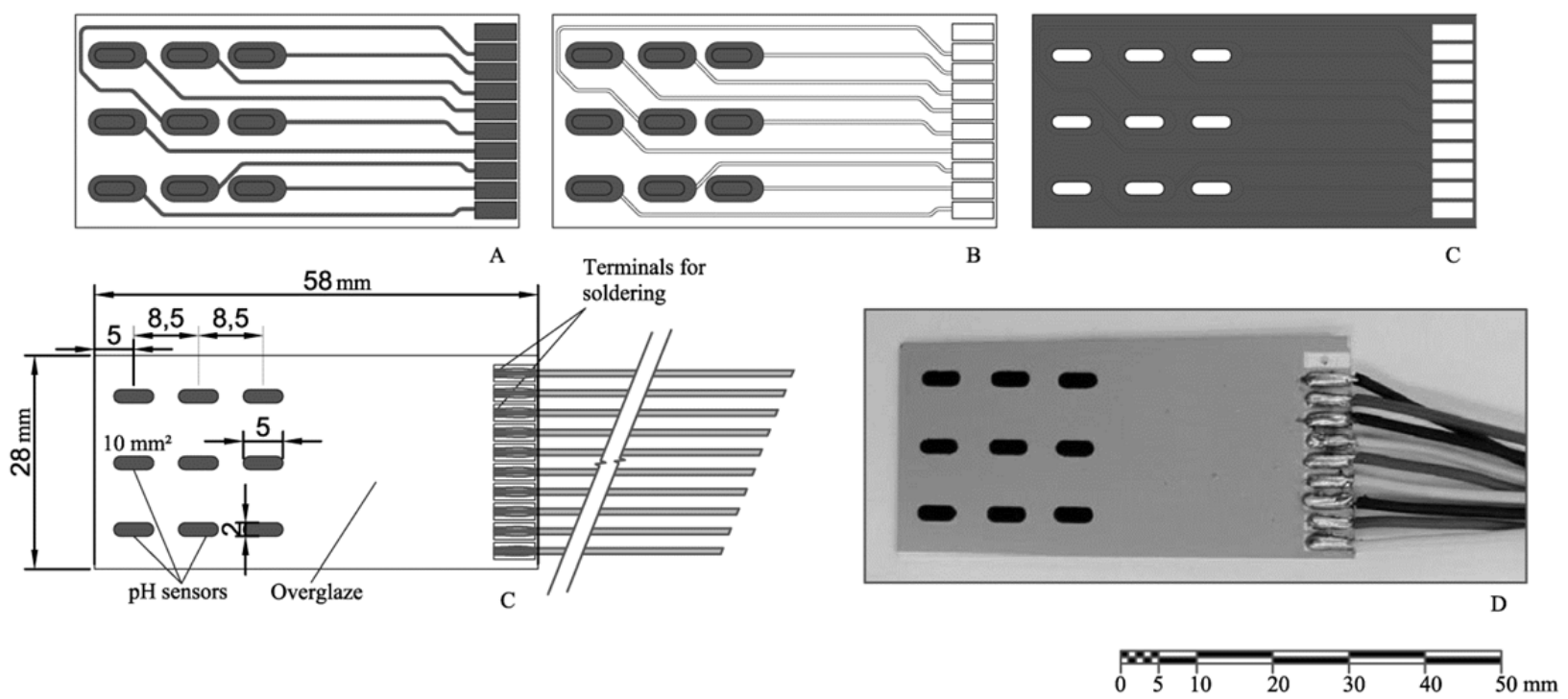

Fig. 1. A) Conductive layer; B) Active layer; C) Protective layer; D) Substrate dimensions; E) Real image

\subsection{Scanning electron microscopy tests}

The study of the three types of commercial resistive pastes was performed with Scanning Electron Microscopy (SEM), model JEOL JSM6300. SEM images were obtained from resistive pastes in order to analyse their composition and verify that there were not any superficial defects in the electrode surface.

Table 1. EDS analysis results from the three analysed pastes.

\begin{tabular}{|c|c|c|c|c|c|c|}
\hline \multirow{2}{*}{ Element } & \multicolumn{2}{|c|}{ Type 1} & \multicolumn{2}{|c|}{ Type 2} & \multicolumn{2}{|c|}{ Type 3} \\
\hline & $\begin{array}{c}\text { Weight } \\
(\%)\end{array}$ & $\begin{array}{c}\text { Moles } \\
(\%)\end{array}$ & $\begin{array}{c}\text { Weight } \\
(\%)\end{array}$ & $\begin{array}{c}\text { Moles } \\
(\%)\end{array}$ & $\begin{array}{c}\text { Weight } \\
(\%)\end{array}$ & $\begin{array}{c}\text { Moles } \\
(\%)\end{array}$ \\
\hline $\mathrm{Na}(\mathrm{K})$ & 1.92 & 3.72 & 1.54 & 2.26 & & \\
\hline Al (K) & 4.88 & 8.05 & 48.65 & 60.81 & & \\
\hline $\mathrm{Si}(\mathrm{K})$ & 34.55 & 54.75 & 2.23 & 2.68 & 16.8 & 46.37 \\
\hline $\mathrm{S}(\mathrm{K})$ & 4.24 & 5.89 & & & & \\
\hline $\mathrm{Cl}(\mathrm{K})$ & 2.48 & 3.11 & 0.35 & 0.34 & & \\
\hline $\mathrm{Ca}(\mathrm{K})$ & 3.98 & 4.42 & 0.19 & 0.16 & 3.92 & 7.59 \\
\hline Mn (K) & 0.97 & 0.79 & & & 4.00 & 5.65 \\
\hline Ag (L) & 46.43 & 19.16 & & & & \\
\hline $\mathrm{Pb}(\mathrm{L})$ & 0.55 & 0.12 & & & 44.20 & 16.54 \\
\hline $\mathrm{P}(\mathrm{K})$ & & & 1.57 & 1.71 & & \\
\hline $\mathrm{K}(\mathrm{K})$ & & & 0.17 & 0.15 & & \\
\hline $\mathrm{Ti}(\mathrm{K})$ & & & 46.29 & 31.89 & & \\
\hline $\mathrm{Ru}(\mathrm{K})$ & & & & & 31.08 & 23.85 \\
\hline
\end{tabular}


Table 1 contains the average paste compositions obtained from the surface studies. The main electroactive element in the Type 1 sensor was silver, followed by small quantities of manganese and lead. In the second type, the only electroactive element present was titanium, and for the Type 3 electrodes, the main element was ruthenium, followed by lead and manganese.

\subsection{Studies in Solution}

The study of the sensors was carried out in four different media, simulating concrete pore solution with different carbonation degrees. Four systems were prepared as follows: a) $0.1 \mathrm{M} \mathrm{NaHCO}_{3}$ at $\mathrm{pH} 8.37$, b) $\mathrm{NaHCO}_{3}(0.015 \mathrm{M}) / \mathrm{Na}_{2} \mathrm{CO}_{3}(0.005 \mathrm{M})$ at $\mathrm{pH} 9.69$, c) $\mathrm{Na}_{2} \mathrm{CO}_{3} 0.1 \mathrm{M}$ at $\mathrm{pH} 11.14$ and d) a saturated $\mathrm{Ca}(\mathrm{OH})_{2}$ solution at $\mathrm{pH}$ 12.57. The measurements were verified with a pH meter (Crison GLP-22) and a Crison ref. 52-02 glass electrode. The measurements were taken inside a Faraday cage and a cryothermostat was used to ensure a constant working temperature of $25^{\circ} \mathrm{C}$.

According to previous tests made in our laboratory [30], conditioning of the sensors was done for $8 \mathrm{~h}$ through alternating immersions in nitric acid $(\mathrm{pH}$ 5) and sodium hydroxide ( $\mathrm{pH}$ 12.5) prepared dissolutions for 15-minute periods. The conditioning was done to improve both sensitivity and response time. After each immersion, the sensor was rinsed with distilled water and later dried with paper. After conditioning, the sensors were successively immersed in the four prepared solutions (with $\mathrm{pH}$ values of 8.37, 9.69, 11.14 and 12.57) and sensitivity, response time, reversibility, response against temperature and chloride interference were analyzed.

The sensitivity, response time and reversibility studies were done with four different sensors and the test was repeated twice. The study on the influence of temperature was also done in the four prepared solutions, working at three different temperatures: 10,25 and $40{ }^{\circ} \mathrm{C}$. In this case two sensors were used and the test was repeated twice, the result being the arithmetic mean of the four values. Finally, anion chloride interference was studied to verify the effect of the presence of this ion on the electric potential value of the $\mathrm{pH}$ sensor. Following the IUPAC [31] recommendations, the study was carried out using the fixed primary ion method. Again, the experiment was done at the four $\mathrm{pH}$ values (12.6, 11.14, 9.6 and 8.37), keeping the $\mathrm{pH}$ constant and increasing the interferent concentration from $10^{-6} \mathrm{M}$ to $10^{-1} \mathrm{M}$ or until a certain concentration of interferent generated a potential variation of $17.7 \mathrm{mV}$ with regard to the initial, which was equivalent to double the value of the main ion activity. 


\subsection{Measurements in concrete specimens}

To observe the response of the sensors attached to the concrete, four cubic samples $(10 \times 10 \times 10 \mathrm{~cm})$ were made using low quality concrete to facilitate the diffusion process of $\mathrm{CO}_{2}$ and the matrix carbonation. CEM II / B-M (S-L) 42.5 R blend cement with limestone filler L and slag S as mineral additions (EN 197-1:2011), and two types of crushed limestone aggregates, gravel (coarse aggregate) 4/12 and sand (fine aggregate) 0/4 were used to make the concrete.

The content of superplasticizer, which in this case was a policarboxylate based admixture (Viscocrete 3425), was adjusted to achieve a slump of $140 \mathrm{~mm}$ in the Abrams cone. Mix proportions are collected in Table 2.

Table 2. Mix proportions and mechanical properties of concrete

\begin{tabular}{ccccccc}
\hline $\begin{array}{c}\text { Cement } \\
\left(\mathrm{kg} / \mathrm{m}^{3}\right)\end{array}$ & $\begin{array}{c}\text { Water } \\
\left(1 / \mathrm{m}^{3}\right)\end{array}$ & $\mathrm{w} / \mathrm{c}$ & $\begin{array}{c}\text { Admixture } \\
\left(\mathrm{kg} / \mathrm{m}^{3}\right)\end{array}$ & $\begin{array}{c}\text { Coarse aggregate } \\
\left(\mathrm{kg} / \mathrm{m}^{3}\right)\end{array}$ & $\begin{array}{c}\text { Fine aggregate } \\
\left(\mathrm{kg} / \mathrm{m}^{3}\right)\end{array}$ & $\begin{array}{c}\mathrm{f}_{\mathrm{c}} \\
(\mathrm{MPa})\end{array}$ \\
\hline 250 & 162.5 & 0.65 & 2.2 & 700 & 1298 & 31.4 \\
\hline (f $\mathrm{f}$ c compressive strength with cylindrical specimen at 28 days $)$
\end{tabular}

Before casting, the multisensor was put in the specimen's centre, placing the first electrode row (three electrodes) at a depth of $14.8 \mathrm{~mm}$ and pulling out the cables through the opposite side (Fig. 2). According to the requirements specified in European standard EN-12390-2 for making test specimens, the moulds were filled by layers, compacting the concrete with an internal needle vibrator.

The specimens were demoulded 48 hours after casting and were kept in a curing chamber at $20^{\circ} \mathrm{C}$ with a relative humidity of $95 \%$ for up to 14 days. Subsequently, they were stored in the laboratory at room temperature for two more weeks and then were subjected to an accelerated carbonation test in a climatic chamber at $26^{\circ} \mathrm{C}$ and with a $30 \% \mathrm{CO}_{2}$ concentration. A salt bridge with connection to the outer reference electrode (SCE) was arranged before the carbonation test and waterproof paint was applied to all sides of the specimen except for the one closer to the electrodes in order to allow $\mathrm{CO}_{2}$ to enter only through that side.

The duration of the accelerated carbonation process was 456 hours (19 days).

After this process, the specimens were divided in two (indirect tensile test) and the broken surface was sprayed with phenolphthalein indicator solution to determine the carbonation depth. 


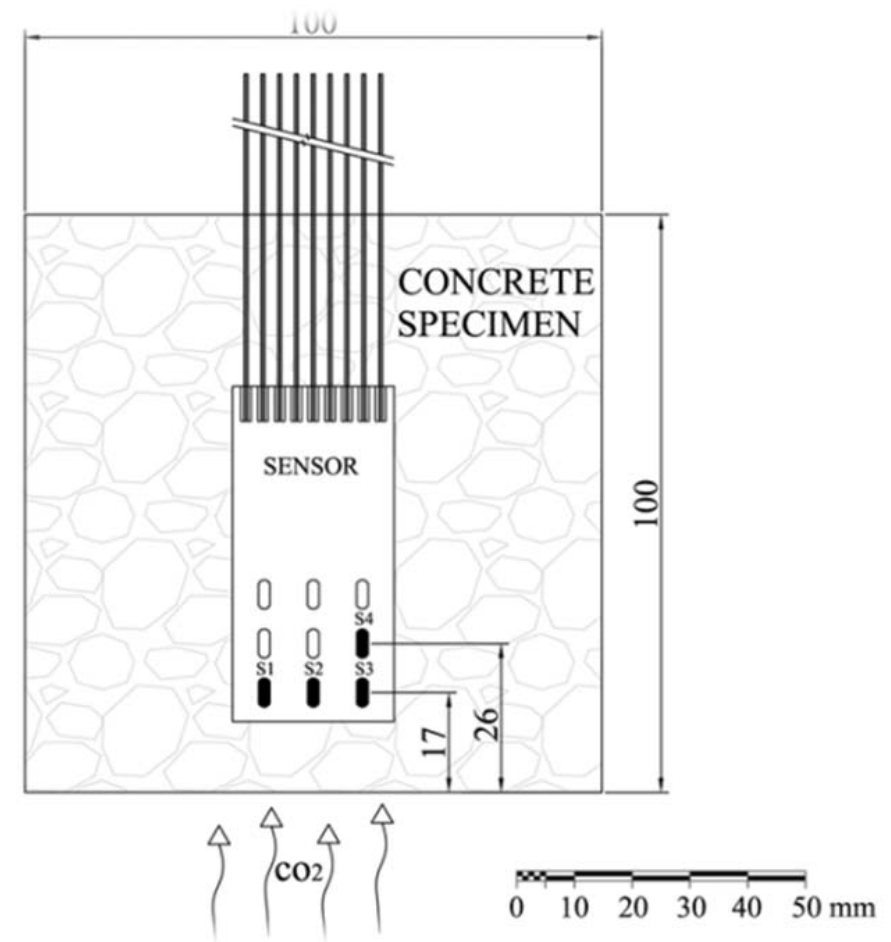

Fig. 2. Sensor location scheme (distances in $\mathrm{mm}$ ).

\subsection{Electrochemical Measurements: Data acquisition system}

Measurements were performed against a reference electrode SCE (Saturated Calomel Electrode: $\mathrm{Hg} / \mathrm{Hg}_{2} \mathrm{Cl}_{2} / \mathrm{KCl}$ (sat), Radiometer Analytical XR110, $+242 \mathrm{mV}$ vs NHE). For potentiometric measurements two different instruments were used: a Crison GLP-22 $\mathrm{pH}$ meter to verify the $\mathrm{pH}$, and a 16-channel potentiometer with an OPA129P operational amplifier with high impedance inputs $\left(10^{15} \Omega\right)$ and a data acquisition card ADLINK PCI9112, inserted into the PCI bus slot of a personal computer.

The acquisition resolution of the measurements was $\pm 0.6 \mathrm{mV}$. Software was developed to provide a suitable graphical user interface with interactive, real-time information on screen (Fig. 3). The program provides simultaneous readings of all inputs at the selected sampling frequency.

To reduce the noise from the potentiometric signal, the equipment was placed in a Faraday box. The internal connection cables were also shielded. By doing this, the noise was reduced considerably, obtaining potential curves with values that did not exceed $2 \mathrm{mV}$ of electrical noise. 


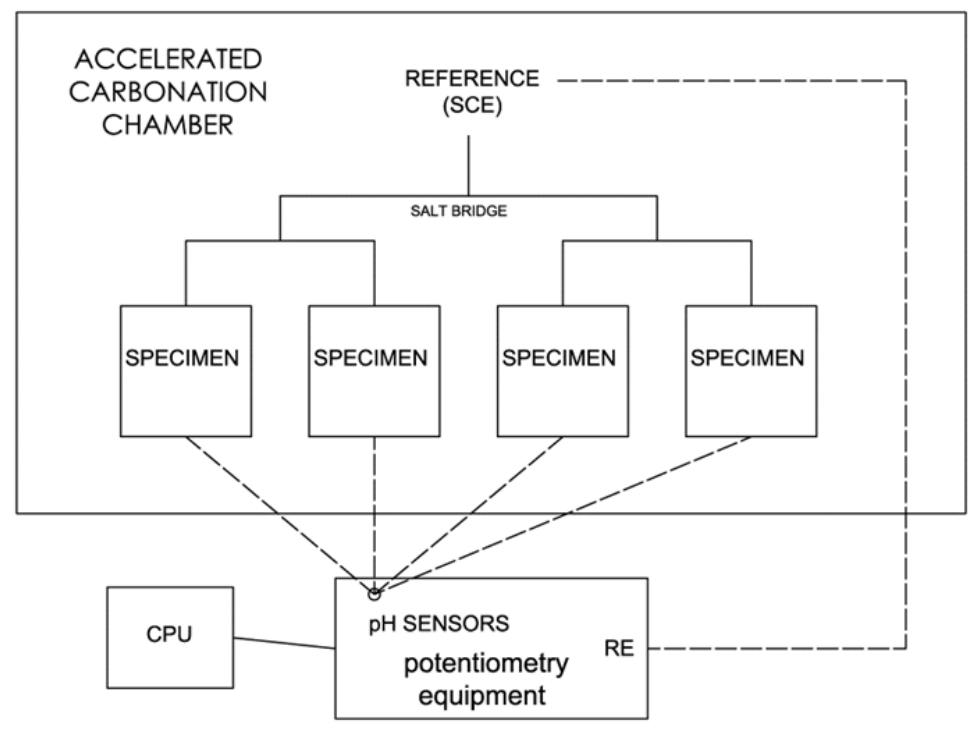

Fig. 3. Data acquisition system.

\subsection{TGA tests}

Samples of concrete taken at 10,20,30,40,50 and $60 \mathrm{~mm}$ from the carbonated surface in the concrete specimen were crushed; then, the coarse aggregate was removed and the samples were ground in acetone, dried at $60{ }^{\circ} \mathrm{C}$ for 30 minutes and stored under argon (to avoid further carbonation) until thermogravimetric analyses were carried out. Thermogravimetric (TG) analyses were performed in a TGA 850 Mettler-Toledo thermobalance at a heating rate of $10^{\circ} \mathrm{C} \min ^{-1}$ from $35^{\circ} \mathrm{C}$ to $600{ }^{\circ} \mathrm{C}$ using sealed pin-holed aluminium crucibles (40 mg of material was tested). A nitrogen flow rate of $75 \mathrm{~mL} \mathrm{~min}^{-1}$ was used for removing the generated gases.

\section{Results and discussion}

\subsection{Studies in solution}

Before testing the sensor response in concrete specimens, the electrochemical behaviour of different sensors was characterised in solution.

\subsection{Sensor conditioning}

The conditioning was done to improve both sensitivity and response time, since according to the oxygen interspersion theory, the active surface needs hydration to respond adequately to $\mathrm{pH}$ variations [23]. In fact, 
Fig. 4 shows that at the end of the electrochemical conditioning process, the sensors reached potential values that were much more reproducible and the time needed to reach a stable potential decreased (sensor response time).

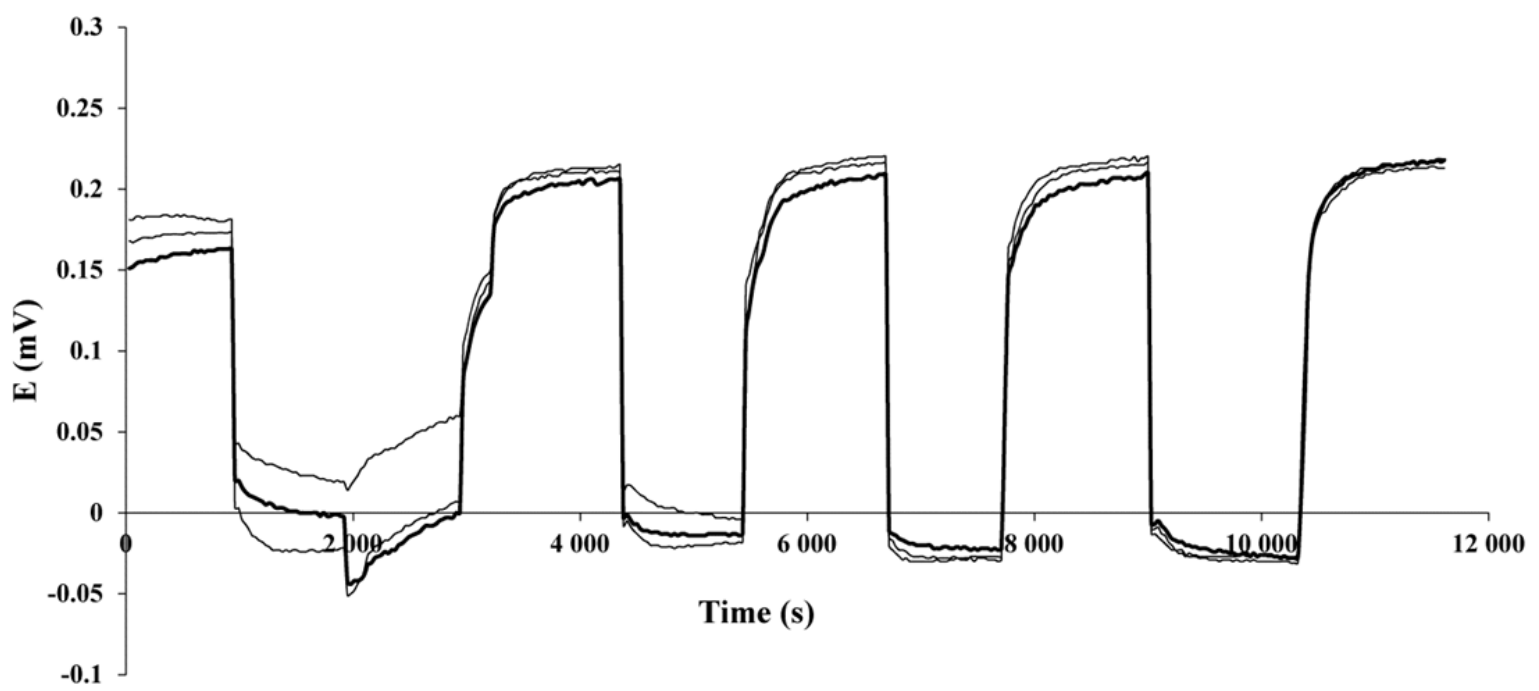

Fig. 4. Sensor conditioning. Converging the evolution of the obtained signal with three different sensors made of silver oxide against time.

\subsubsection{Calibration and Sensitivity studies}

Sensitivity is the parameter which characterises the electrode response. When analysing the potentiometric response of the electrode based on the $\mathrm{pH}$, sensitivity is given by the slope of the rectilinear segment seen in the potential against $\mathrm{pH}$ graph, expressed in $\mathrm{mV}$ per $\mathrm{pH}$ unit $\left(\mathrm{mV} \cdot \mathrm{pH}^{-1}\right)$. In Fig. 5, values obtained are shown for the three types of pastes studied: $\mathrm{Ag}_{2} \mathrm{O}$ (Type 1), $\mathrm{TiO}_{2}$ (Type 2) and $\mathrm{RuO}_{2}$ (Type 3), and in Table 3 sensitivity values and standard potential $\mathrm{E}_{0}$ are collected.

Under ideal conditions, the sensor should have a Nernstian behaviour, with a linear response to $\mathrm{pH}$ variations and a slope of $-59.16 \mathrm{mV} \cdot \mathrm{pH}^{-1}$ at $25^{\circ} \mathrm{C}$. Table 3 shows the experimental values of the different sensors manufactured with different compositions of electroactive pastes. As is observed in Fig. 5 and Table 3, the slope obtained with the three resistive pastes is a little bit lower than the theoretical one, with $\mathrm{Ag}_{2} \mathrm{O}$ (Type 1) being the one that presents the best response to $\mathrm{pH}$ variations, since the slope is $-54.8 \mathrm{mV} \cdot \mathrm{pH}^{-1}$. 


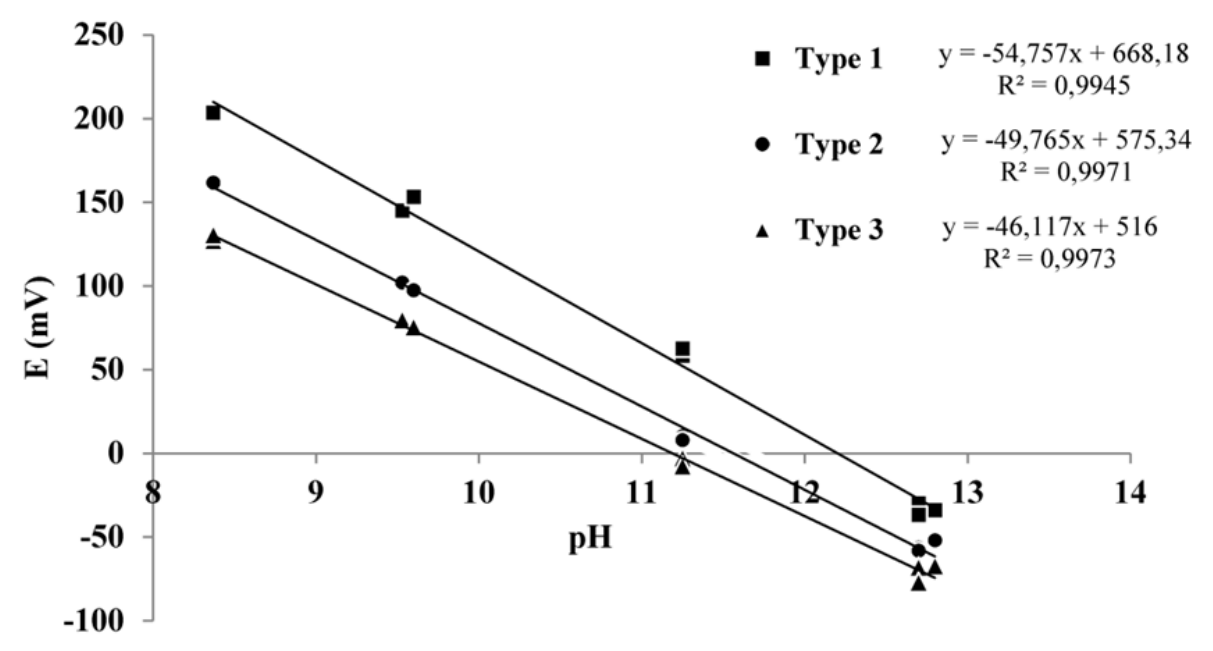

Fig. 5. Graphs showing potential against $\mathrm{pH}$ belonging to the three types of pastes used at $25^{\circ} \mathrm{C}$.

Table 3 . Sensitivity and average standard potential at $25^{\circ} \mathrm{C}$ (vs SCE)

\begin{tabular}{ccc}
\hline Paste & $\begin{array}{c}\text { Sensitivity } \\
(\mathrm{mV} / \mathrm{pH})\end{array}$ & $\begin{array}{c}\mathrm{E}_{0} \\
(\mathrm{mV})\end{array}$ \\
\hline Type 1 & -54.8 & 668 \\
Type 2 & -49.8 & 575 \\
Type 3 & -46.1 & 515 \\
\hline
\end{tabular}

The difference observed with the theoretical value $-59.16 \mathrm{mV} \cdot \mathrm{pH}^{-1}$ is due to the electrode sensitivity, which depends on the composition of the resistive paste. Commercial pastes include secondary components, generally melting elements such as lead boron silicates for its relatively low melting point. If lead additives are present, the number of exchanged electrons (n) may vary between $1 \leq n<2$, since $A g(n=1), \operatorname{Ti}(n=1)$ and $\mathrm{Pb}(\mathrm{n}=2)$ are elements which can easily oxidize. In a previous study, we demonstrated that the slope of the line for the potential against $\mathrm{pH}$ in a mixture of electroactive species $[32,33]$ met the requirements of the following equation:

$$
\text { Slope }=\frac{2.303 \mathrm{R} \mathrm{T}}{\mathrm{n}_{\text {TOTAL }} \mathrm{F}}
$$

where $R$ is the universal perfect gas constant $(8.314 \mathrm{~J} / \mathrm{K} \mathrm{mol}), T$ is the temperature $(\mathrm{K}), \mathrm{n}$ is the number of electrons involved and F is Faraday's constant (96485 C/mol). 
It can be assumed that the number of exchanged electrons by the metallic oxides $\mathrm{Ag}_{2} \mathrm{O}, \mathrm{TiO}_{2}$ and $\mathrm{RuO}_{2}$ during the redox process is 1 electron, whereas for lead it is 2 electrons, changing from $\mathrm{Pb}(\mathrm{II})$ to $\mathrm{Pb}(\mathrm{IV})$ or from $\mathrm{Pb}(0)$ to $\mathrm{Pb}(\mathrm{II})$. Knowing the molar percentage of the active oxides (Table 1) that exchange 1 electron and the ones that exchange two, the total value of exchanged electrons can be calculated through the following expression:

$$
\mathrm{n}_{\text {TOTAL }}=1 \cdot \frac{\sum_{\mathrm{i}=1}^{\mathrm{n}} v_{\mathrm{Mi}-1}}{\sum_{\mathrm{i}=1}^{\mathrm{n}} v_{\mathrm{Mi}-1}+\sum_{\mathrm{i}=1}^{\mathrm{n}} v_{\mathrm{Mi}-2}}+2 \cdot \frac{\sum_{\mathrm{i}=1}^{\mathrm{n}} v_{\mathrm{Mi}-2}}{\sum_{\mathrm{i}=1}^{\mathrm{n}} v_{\mathrm{Mi}-1}+\sum_{\mathrm{i}=1}^{\mathrm{n}} v_{\mathrm{Mi}-2}}
$$

where $v_{\mathrm{Mi}-1}$ is the number of moles of $\mathrm{M}_{\mathrm{i}}$ metals which exchange 1 electron and $v_{\mathrm{Mi}-2}$ the number of moles of $\mathrm{M}_{\mathrm{i}}$ metals which exchange 2 electrons.

Table 4 shows the experimental exchanged electrons for each paste calculated from the slopes and the theoretical exchanged electrons obtained from equation 2. It is observed that for the silver paste (Type 1), the total number of exchanged electrons is 1.08 and the theoretical is 1.01 , both values being very close. For the ruthenium paste (Type 3) there was a large lead content in its composition, and this is the reason why the slope is so low. When molar fractions of the active oxides are calculated, the total number of exchanged electrons is 1.36 (according to eq. 2). This value is also similar to the estimation based on the slope obtained experimentally, $n=1.28$. Nevertheless, for the titanium paste (Type 2), it was not possible to justify the slope with the obtained results.

Table 4. Number of exchanged electrons for each paste.

\begin{tabular}{ccc}
\hline & $\begin{array}{c}\text { THEORETICAL } \\
\mathrm{n}_{\text {TOTAL }}\end{array}$ & $\begin{array}{c}\text { EXPERIMENTAL } \\
\mathrm{n}_{\text {TOTAL }}\end{array}$ \\
\hline Type 1 & 1.01 & 1.08 \\
Type 2 & 1.00 & 1.19 \\
Type 3 & 1.36 & 1.28 \\
\hline
\end{tabular}

\subsubsection{Response time and reversibility}

The response time parameter determines the speed at which the sensor reads the potential of the solution in which it is immersed. In Fig. 6, experimental values and their corresponding setting curve to the given response by a sensor when moving from $\mathrm{pH} 12.6$ to 8.37 are represented. 


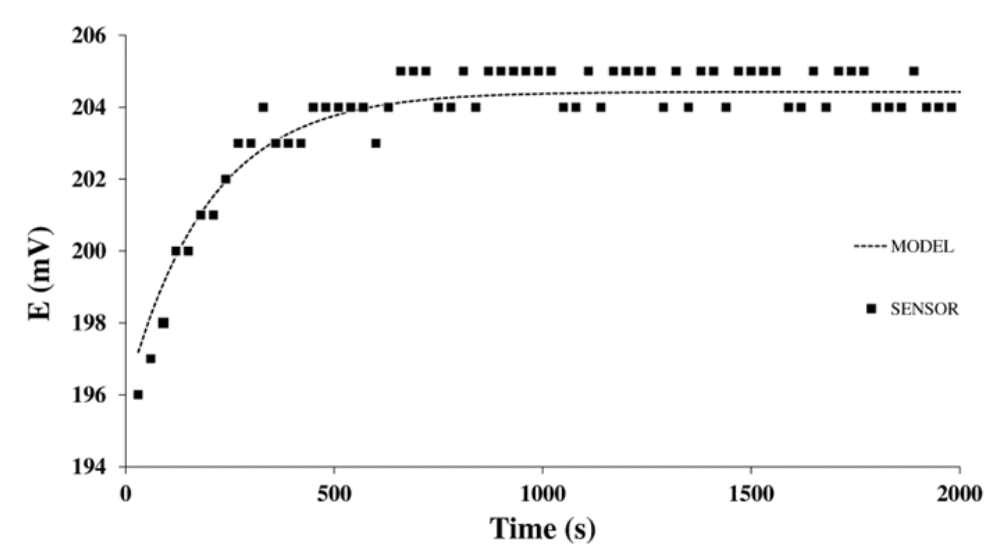

Fig. 6. Experimental data obtained with a sensor and corresponding fit.

To calculate the setting curve, a first order kinetic model was adopted, where the response speed (v) is proportional to the existing potential difference between the potential value of the electrode in a given moment $(E)$ and the final or stable potential $\left(\mathrm{E}_{\mathrm{F}}\right)$ :

$$
\mathrm{E}=\mathrm{E}_{\mathrm{F}}-\left(\mathrm{E}_{\mathrm{F}}-\mathrm{E}_{0}\right) \mathrm{e}^{-\mathrm{kt}}
$$

where $E_{0}$ is the potential when $t=0, E_{F}$ is the final potential, $k$ is the speed constant of the electrode response and $\mathrm{t}$ is the elapsed time. Using the Solver analysis tool in Microsoft Excel, the value of the $\mathrm{k}$ constant was obtained so that the average quadratic error between the experimental and the theoretical values was the lowest. Once the equation for the setting curve is known, the response time $\left(\tau_{R}\right)$ can be calculated. The response time was considered the time required to reach $95 \%$ of the stable potential and it was calculated from the results obtained from the reversibility test. Therefore, implementing the previous equation (Eq. 3) for the particular case of $\mathrm{E}=0.95\left(\mathrm{E}_{\mathrm{F}}-\mathrm{E}_{0}\right)+\mathrm{E}_{0}$, we have:

$$
\tau_{\mathrm{R}}=\frac{-\ln 0.05}{\mathrm{k}}
$$

The obtained response times and speed constants for the different pastes are shown in Table 5. Again, the best behaviour was obtained with the Type 1 pastes, with pastes 2 and 3 having lower response times. Type 1 paste response time $\left(\tau_{R}\right)$ average values were close to 600 seconds. Therefore, it is possible to assume that the $\mathrm{pH}$ sensor has good response time with respect to its future concrete application. 
Table 5. Speed constants and mean response times obtained based on $\mathrm{pH}$ variation.

\begin{tabular}{cccc}
\hline Paste & pH variation & $\begin{array}{c}\mathrm{k} \\
\left(\mathrm{s}^{-1}\right)\end{array}$ & $\begin{array}{c}\tau_{\mathrm{R}} \\
(\mathrm{s})\end{array}$ \\
\hline Type 1 & from 12.60 to 11.14 & 0.00479 & 625 \\
& from 12.60 to 9.60 & 0.00367 & 815 \\
& from 12.60 to 8.37 & 0.00507 & 590 \\
Type 2 & from 12.60 to 11.14 & 0.00171 & 1751 \\
& from 12.60 to 9.60 & 0.00355 & 843 \\
& from 12.60 to 8.37 & 0.00278 & 1077 \\
Type 3 & from 12.60 to 11.14 & 0.00327 & 913 \\
& from 12.60 to 9.60 & 0.00220 & 1358 \\
& from 12.60 to 8.37 & 0.00285 & 1049 \\
\hline
\end{tabular}

For the reversibility test, Type 1 sensors were used because they showed the most Nernstian-like behavior to $\mathrm{pH}$ variations. Fig. 7 shows the potential response of four sensors (and two replays of the test) during the different stages of the experiment ( 7 stages) and Table 6 gives the results obtained from the sensors after stabilizing the potential in each stage of the test. In the graph, a clear response to $\mathrm{pH}$ change can be observed, with well-defined steps and with the higher potentials referring to the more acidic solutions.

Table 6. Potential (SCE) of the sensors at the end of the seven test stages

\begin{tabular}{ccccccccc}
\hline Test & Sensor & \multicolumn{7}{c}{$\mathrm{pH}$} \\
& & 12.60 & 11.14 & 12.60 & 9.60 & 12.60 & 8.37 & 12.60 \\
\hline 1 & Sensor 1 & -37 & 63 & -38 & 140 & -36 & 203 & -35 \\
& Sensor 2 & -35 & 65 & -39 & 147 & -37 & 202 & -38 \\
& Sensor 3 & -39 & 61 & -35 & 144 & -39 & 203 & -39 \\
& Sensor 4 & -34 & 61 & -38 & 150 & -36 & 208 & -39 \\
& Average value & -36.3 & 62.5 & -37.6 & 145.3 & -37.0 & 204.0 & -37.6 \\
& Sensor 1 & -36 & 63 & -34 & 145 & -39 & 205 & -42 \\
& Sensor 2 & -35 & 60 & -37 & 144 & -37 & 204 & -34 \\
& Sensor 3 & -34 & 57 & -39 & 148 & -36 & 204 & -39 \\
& Sensor 4 & -35 & 56 & -35 & 148 & -36 & 201 & -32 \\
& Average value & -35.0 & 59.0 & -36.3 & 146.3 & -37.0 & 203.5 & -36.8 \\
\hline
\end{tabular}




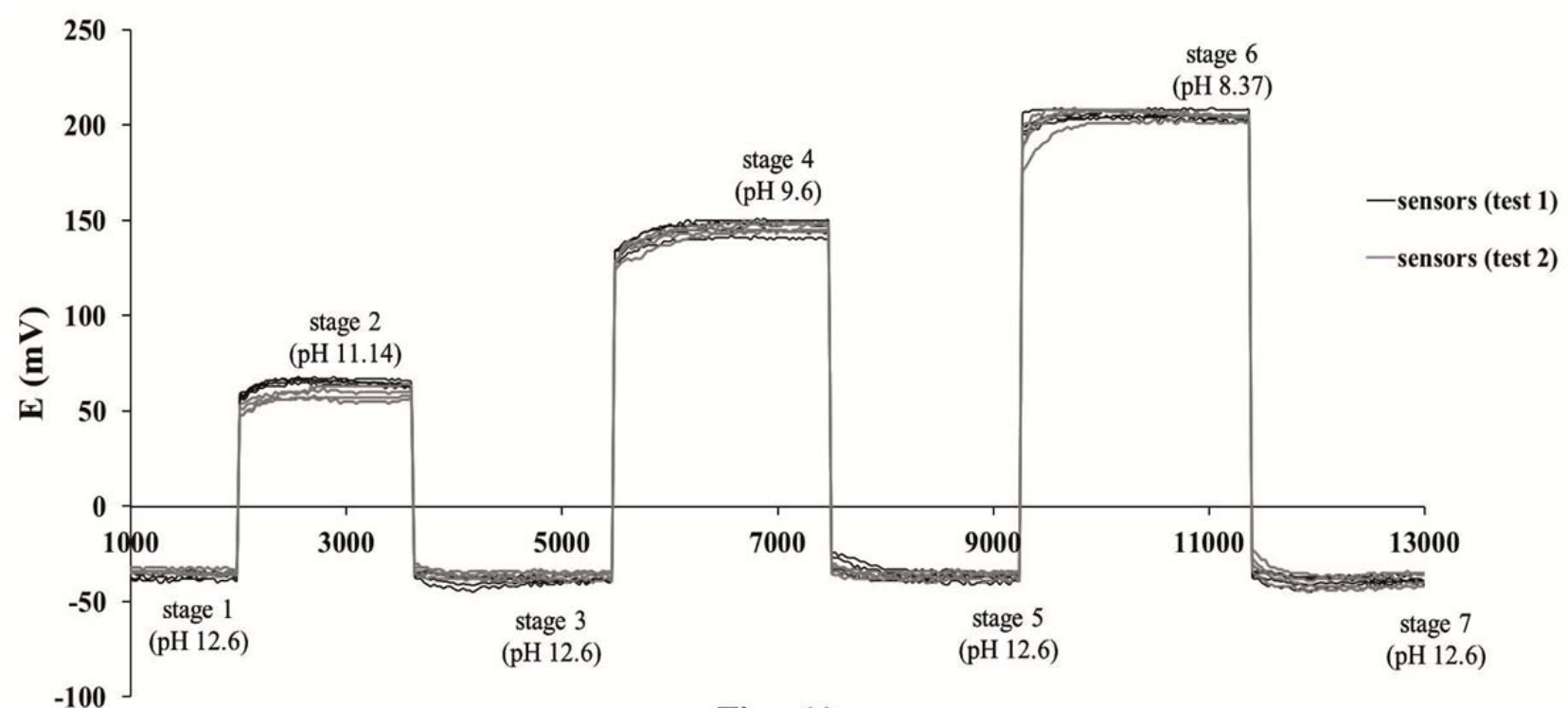

Time (s)

Fig. 7. Reversibility test for Type 1 sensors (four sensors). Potential (SCE) vs time (s). Stage 1: $\mathrm{pH}$ 12.6;

Stage 2: pH 11.14; Stage 3: pH 12.6; Stage 4: $\mathrm{pH}$ 9.6; Stage 5: pH 12.6; Stage 6: pH 8.37; Stage 7: pH 12.6.

An Analysis of Variance (ANOVA) with 3 crossed factors (Sensor, Test stage and Test replay) was carried out to analyse if the electrochemical response of all the sensors was the same and to study their reversibility. The analysis shows that the potential values obtained when the test is repeated are quite similar to those initially obtained, with no statistically significant differences between them (p-value $=0.92$ ) for a $95 \%$ confidence level. The results also show that the response of the different sensors is very similar $(\mathrm{p}$-value $=$ $0.43)$.

The average standard deviation of the results was $2.20 \mathrm{mV}$. To study the reversibility of the sensors, the ANOVA was only done with the corresponding potential values of the initial test stage (solution $\mathrm{pH} 12.60$ ) and the values of the three different stages where sensors were placed in the same solution (Fig. 7: stages 1, $3,5$ and 7$)$.

Again, no statistically significant differences were detected between the four stages ( $p$-value $=0.47)$. The standard deviation of the obtained results in the four used sensors was $2.39,1.85,2.20$ and $2.18 \mathrm{mV}$, respectively. Taking into account that the sensitivity of the sensors was $54.8 \mathrm{mV} / \mathrm{pH}$, it can also be noted that the sensors exhibit very good reproducibility and reversibility. 


\subsubsection{Electrode response against temperature}

Again, only paste Type 1 was studied because it showed the most Nernstian-like response to $\mathrm{pH}$ variations.

Table 7 gives the values obtained in the test. In Fig. 8 the average values obtained are displayed and in Table 8 theoretical and experimental values of the slope for the different analysed temperatures are shown.

Table 7. Potential response $(\mathrm{mV})$ against temperature

\begin{tabular}{ccccccc}
\hline $\mathrm{T}^{\mathrm{a}}$ & $\mathrm{pH}$ & \multicolumn{2}{c}{ Test 1 } & \multicolumn{2}{c}{ Test 2 } & Average value \\
\cline { 3 - 6 }$\left({ }^{\mathrm{o}} \mathrm{C}\right)$ & & Sensor 5 & Sensor 6 & Sensor 5 & Sensor 6 & \\
\hline 40 & 12.70 & -40 & -34 & -29 & -28 & -32.8 \\
& 11.25 & 66 & 60 & 59 & 63 & 62.0 \\
& 9.60 & 158 & 154 & 149 & 151 & 153.0 \\
& 8.68 & 200 & 203 & 205 & 206 & 203.5 \\
& 12.70 & -29 & -32 & -35 & -32 & -32.0 \\
& 11.25 & 60 & 56 & 57 & 60 & 58.3 \\
& 9.60 & 140 & 147 & 146 & 147 & 145.0 \\
& 8.68 & 183 & 195 & 190 & 184 & 188.0 \\
& 12.70 & -43 & -48 & -45 & -42 & -44.5 \\
& 11.25 & 39 & 46 & 40 & 47 & 43.0 \\
& 9.60 & 121 & 132 & 126 & 126 & 127.0 \\
& 8.68 & 162 & 168 & 168 & 181 & 169.8
\end{tabular}

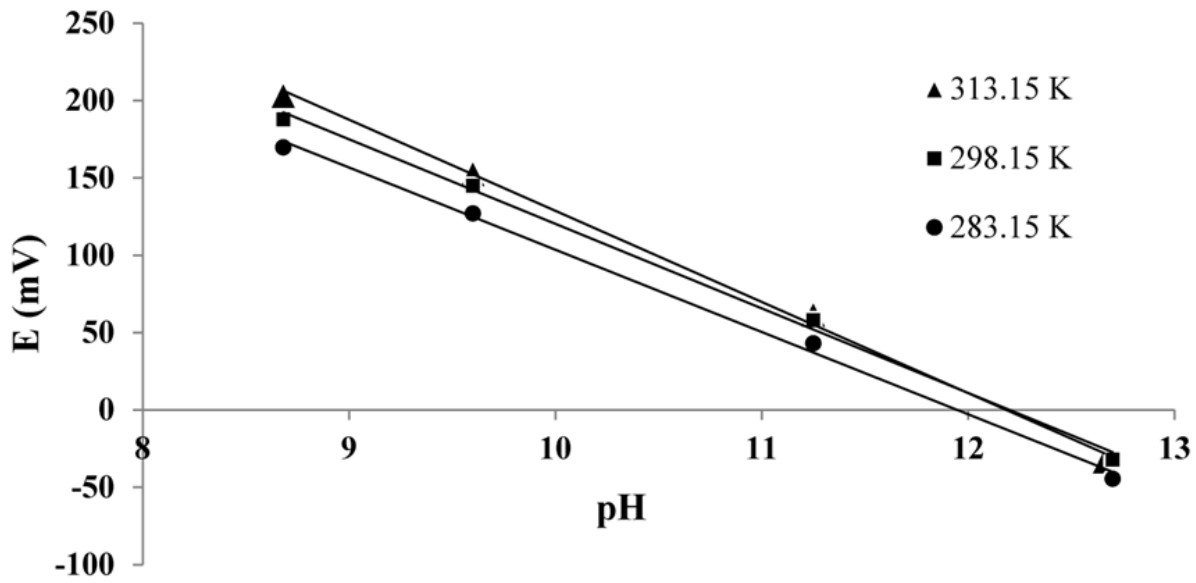

Fig. 8. Sensor calibration lines for Type 1 sensors in solutions at temperatures of 10,25 and $40^{\circ} \mathrm{C}$. 
As seen in Table 8, the experimental results were very similar to the theoretical ones, and therefore it can be said that the average slope increases slightly with the rising of temperature, according to the Nernst equation.

Table 8. Sensitivity and standard average potential variation with respect to temperature for Type 1 sensors.

\begin{tabular}{ccccc}
\hline $\begin{array}{c}\mathrm{T} \\
\left({ }^{\circ} \mathrm{C}\right)\end{array}$ & $\begin{array}{c}\mathrm{T} \\
(\mathrm{K})\end{array}$ & $\begin{array}{c}\text { Theoretical } \\
\text { slope }\end{array}$ & $\begin{array}{c}\text { Experimental } \\
\text { slope }\end{array}$ & $\begin{array}{c}\Delta \mathrm{E}^{\mathrm{o}} \\
(\mathrm{mV})\end{array}$ \\
\hline 40 & 313.15 & -62.0 & -58.9 & 626 \\
25 & 298.15 & -59.2 & -54.7 & 667 \\
10 & 283.15 & -56.1 & -53.2 & 718 \\
\hline
\end{tabular}

The relationship between experimental slope and temperature is linear, with a best-fit line of $\mathrm{R}^{2}=0.93$. Therefore, this is a sub-Nernstian process, due to the contribution of the different active redox metals contained in the sensor paste. The equation that relates the potential read by the sensor for different temperatures within the calibration range to the $\mathrm{pH}$ value is:

$$
\mathrm{pH}=\frac{\mathrm{E}+3.06 \cdot \mathrm{T}-1584}{531-3.388 \cdot \mathrm{T}+0.006 \cdot \mathrm{T}^{2}}
$$

This expression allows $\mathrm{pH}$ values to be obtained from the system when the values read by the Type 1 silver oxide sensor for potential (E) expressed in $\mathrm{mV}$ and temperature (T) expressed in ${ }^{\circ} \mathrm{K}$ are inserted.

\subsubsection{Chloride interference}

Anion chloride interference was studied to verify the effect of the presence of this ion on the electric potential value of the $\mathrm{pH}$ sensor. In Fig. 9 it can be observed the potential variation of the $\mathrm{Ag}_{2} \mathrm{O}$ (Type 1) electrodes at $\mathrm{pH} 9.6$ against $\log \left[\mathrm{Cl}^{-}\right]$. It can be seen that there is a change in the electrode potential when the chloride concentration is around $10^{-2.5} \mathrm{M}$.

The equations that relate the effect of an interferent on the electrode potential have been developed in a previous work [34]. Equation 6 deals with the case of the interference of chloride ions. By fitting the experimental data of the potential against the chloride activity at $\mathrm{pH} 9.6$ (Fig. 9), the potentiometric interference constant (Ki) was obtained using the Solver tool in Microsoft Excel.

$$
\mathrm{E}=\left(E_{\mathrm{Ag}_{2} \mathrm{O} / \mathrm{OH}}^{0}-E_{\mathrm{Hg}_{2} C l_{2} / C l}^{0}\right)-59.16 \cdot \log \left[\left(\mathrm{OH}^{-}\right)+\left(\frac{\mathrm{K}_{\mathrm{ps}}^{\mathrm{Ag}_{2} \mathrm{O}}}{\mathrm{C}_{0}}\right)+\frac{\mathrm{K}_{\mathrm{ps}}^{\mathrm{Ag}_{2} \mathrm{O}}}{\mathrm{K}_{\mathrm{ps}}^{\mathrm{AgCl}}}\left(C l^{-}\right)\right]
$$

where: 


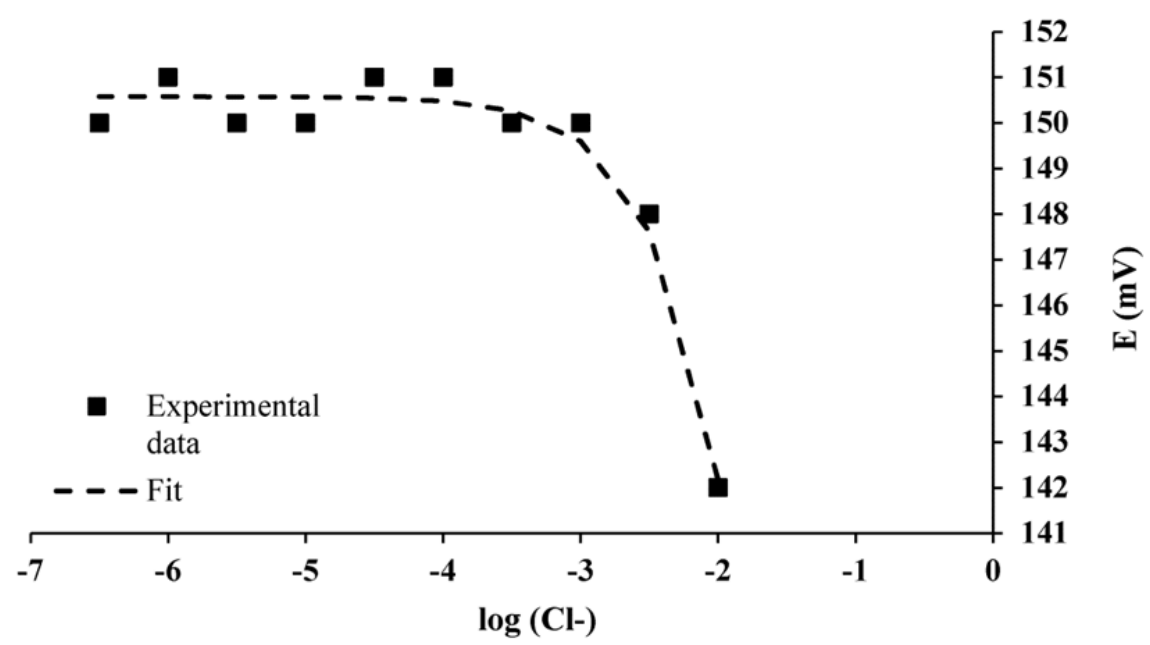

Fig. 9. Potential variation against $\log \left[\mathrm{Cl}^{-}\right]$in a $\mathrm{pH} 9.6$ solution

\subsection{Accelerated carbonation test in hardened concrete}

The test was carried out using only Type 1 (silver oxide) embedded multisensor, because it showed the best electrochemical response to $\mathrm{pH}$ variations in the solution studies. These sensors monitored the changes in potential over time. The value for the average advance of the carbonation front was obtained by the phenolphthalein method, giving as a result $27 \mathrm{~mm}$. Based on this value, the carbonation speed constant of the concrete could be calculated, which in working conditions proved to be equal to $\mathrm{K}=1.26 \mathrm{~mm} / \mathrm{h}^{1 / 2}$. This coefficient is inversely proportional to the resistance to carbonation of the concrete and can be expressed from Fick's first law of diffusion as follows:

$x=K(t)^{0.5}$

where, $\mathrm{x}$ is carbonation depth $(\mathrm{mm}), \mathrm{t}$ is exposure time (hours) and $\mathrm{K}$ is the carbonation coefficient $\left(\mathrm{mm} / \mathrm{h}^{0.5}\right)$. Even though $\mathrm{K}$ may vary with time [35] and, in the case of high strength concretes or concretes exposed to the open air, the exponent 0.5 may differ [35-37], this is the sensors (S4 and S5) at a depth of 26 $\mathrm{mm}$, based on time. At the start of the carbonation process, all the sensors show a $\mathrm{pH}$ near 13 . When the carbonation front reaches the sensors, it produces a large variation in the potential, or $\mathrm{pH}$, with a sigmoidal jump. Taking into account that $\mathrm{CO}_{2}$ diffuses through a heterogeneous medium, it makes sense that there is a certain disparity between the jumps of the sensors located at a same depth (around 8 hours between sensors 
$\mathrm{S} 1$ and S2 and barely 2 hours between S4 and S5). In the sensors located at a lower depth, the jump began to happen at 102 hours after $\mathrm{CO}_{2}$ exposition, whereas the sensors of the second row changed their potential after 174 hours. formula normally adopted to evaluate resistance to carbonation [38,39].

The $\mathrm{pH}$ of the pore solution can be calculated using Equation 5. To calculate this value we assumed that the contact potential on the system: Sensor/Pore Solution/ECS was negligible. Under these conditions, Fig. 10 shows the $\mathrm{pH}$ variation calculated in three sensors (S1, S2 and S3) located at a depth of $17 \mathrm{~mm}$ and two

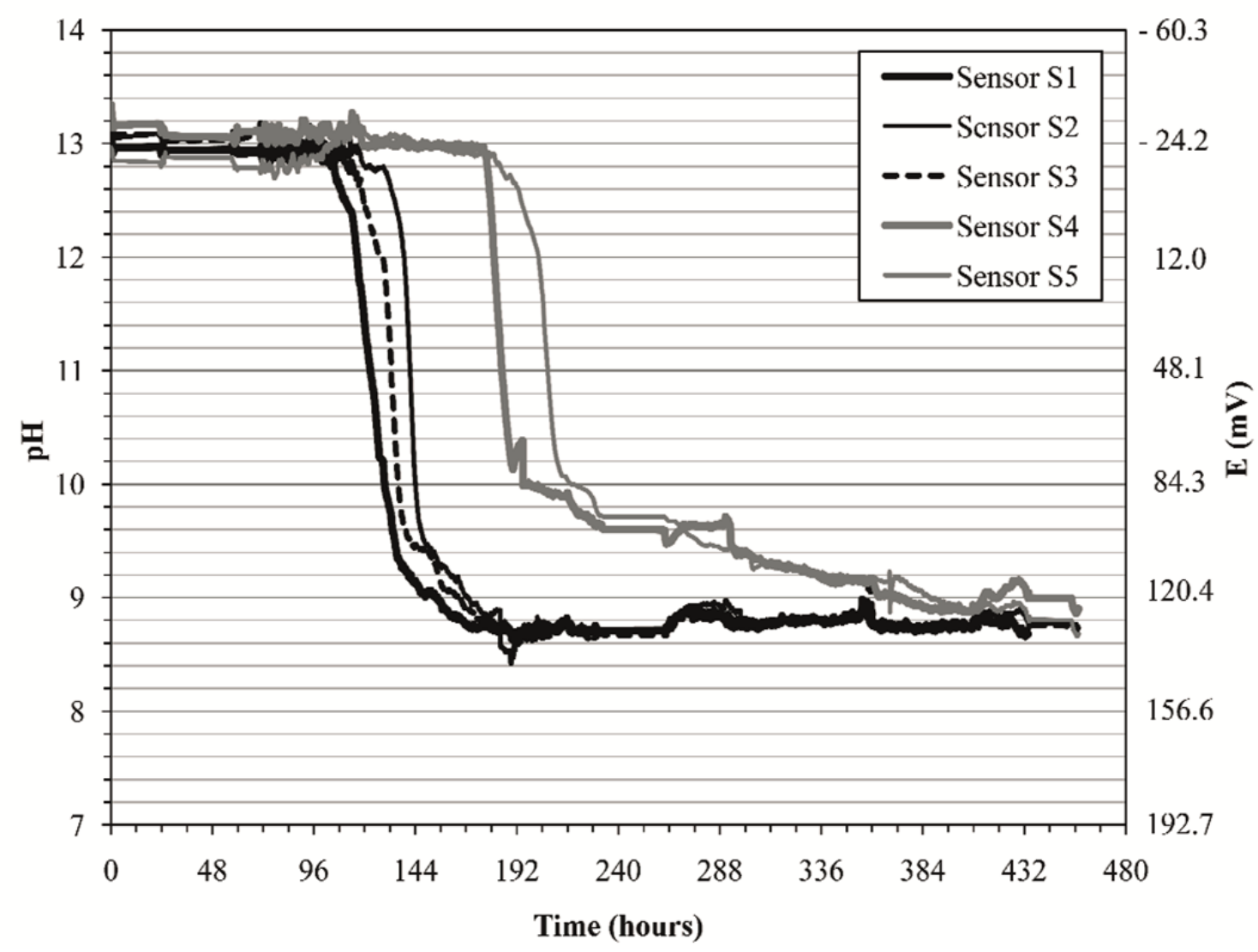

Fig. 10. Variation of $\mathrm{pH}$ and potential over time for 5 sensors in a concrete test specimen subjected to accelerated carbonation testing.

Only after the carbonation front affects the whole surface of the electrode can the electrode potential stabilize (intermediate potential between the carbonated area and the non-carbonated). Therefore, after an initial jump, the potential continued to vary slowly until it reached a constant $\mathrm{pH}$ value around 8.7 . The total variation of the sensor potential of the first and second row was $181 \pm 21 \mathrm{mV}$. In the case of the two sensors located at a greater depth ( $\mathrm{S} 4$ and $\mathrm{S} 5$ ), the stabilization stage was slower. This slow stabilization of the $\mathrm{pH}$ is because carbonation does not exhibit a sharp reaction front since the kinetics of the chemical reactions become the 
rate-controlling processes, rather than the diffusion of $\mathrm{CO}_{2}$ [40]. Also, during the concrete carbonation, a certain amount of water is released, thereby filling up pores and probably hindering even more the advance of $\mathrm{CO}_{2}[41,42]$. Regarding the accelerated carbonation processes, this effect is likely even more noticeable due to the slowness with which the water vapour gradient balances inside the concrete section.

These results suggest that it is feasible to monitor the advance of process of carbonation in mortar and concrete by means of non-destructive monitoring techniques. This tool provides useful information to establish non-destructive diagnosis criteria for the evaluation of the durability of reinforced concrete structures.

To verify the effectiveness of the sensors, once the potential jump of the sensors in the first two rows happened, some specimens were broken in half and the carbonation depth was measured using the phenolphthalein test. In every analysed case, the results were satisfactory, observing that the carbonation depth, according to the phenolphthalein colour, was the same depth at which the sensors that had a change in potential were located. For example, in Fig. 11 the results from one of the samples can be seen, after detecting a change in potential in the sensors located at a depth of $26 \mathrm{~mm}$.

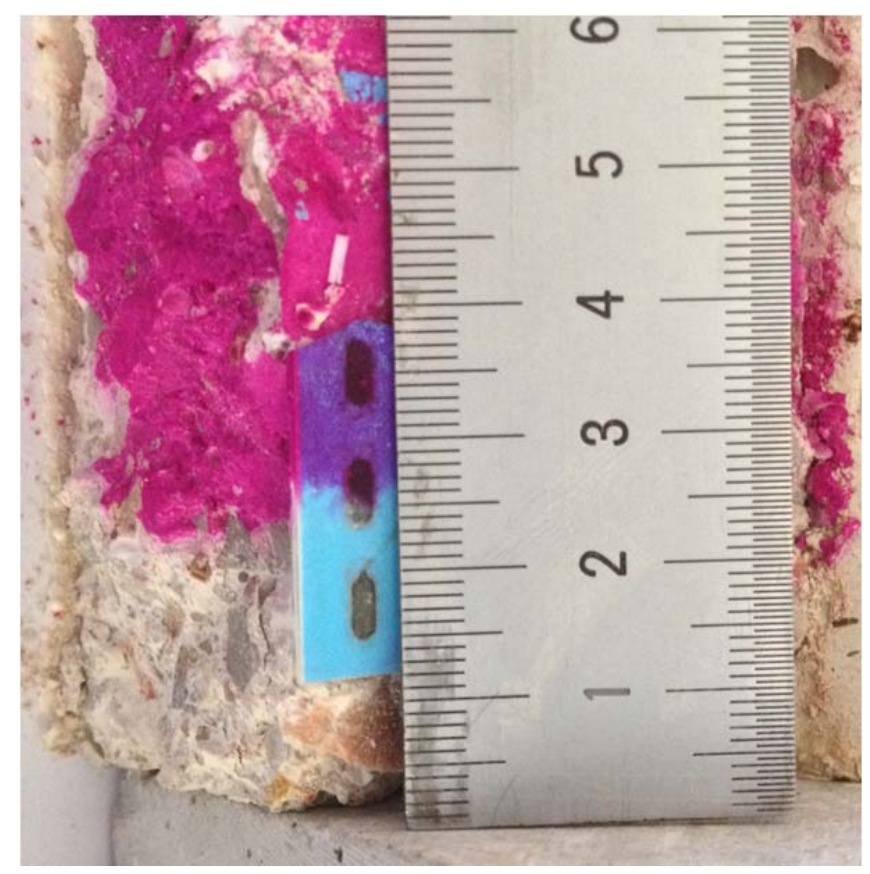

Fig. 11. Phenolphthalein test.

\subsection{Thermogravimetric tests}

Samples of concrete were taken at six different depths after carbonation of the specimen for 456 hours. These samples were analyzed by thermogravimetry, in order to quantify the amount of hydrates present, primarily the amount of calcium hydroxide $\mathrm{Ca}(\mathrm{OH})_{2}$. It is well known [43] that hydration of Portland 
cement yields large amounts of hydrates: calcium silicate hydrates (C-S-H), calcium aluminate, calcium silicoaluminate hydrates and hydrogarnet (C-A-H, C-A-S-H, HG), ettringite (Et) and portlandite or calcium hydroxide $(\mathrm{CH})$. Thermal decompositions of these compounds are produced at different temperatures [44]: C-S-H and Et decompose in the $80-200{ }^{\circ} \mathrm{C}$ range, C-A-H/C-A-S-H in the $200-300{ }^{\circ} \mathrm{C}$ range, hydrogarnet in the $350-450{ }^{\circ} \mathrm{C}$ range, and $\mathrm{CH}$ in the $450-580{ }^{\circ} \mathrm{C}$ range. These temperature decomposition ranges could vary depending on the analysis conditions (e.g., the amount of the sample, heating rate, use of open or sealed/pinholed crucibles). Fig. 12 shows the thermogravimetric curve (TG) and its corresponding derivative curve (DTG) for a non-carbonated zone (60 $\mathrm{mm}$ from the carbonated surface). In this figure, it can be see that there is a continuous mass loss when heating in the $100-600{ }^{\circ} \mathrm{C}$ range. Some peaks in the DTG curve are showed: peaks at 111,123 and $139^{\circ} \mathrm{C}$ correspond to the dehydration of C-S-H and Et; peaks at $208{ }^{\circ} \mathrm{C}$ and $262{ }^{\circ} \mathrm{C}$ are attributed to $\mathrm{C}-\mathrm{A}-\mathrm{H} / \mathrm{C}-\mathrm{A}-\mathrm{S}-\mathrm{H}$; at $431^{\circ} \mathrm{C}$ for hydrogarnet and, finally, the peak centred at $547{ }^{\circ} \mathrm{C}$ is due to the decomposition of portlandite according to the following chemical reaction:

$$
\mathrm{Ca}(\mathrm{OH})_{2} \Rightarrow \mathrm{CaO}+\mathrm{H}_{2} \mathrm{O}
$$

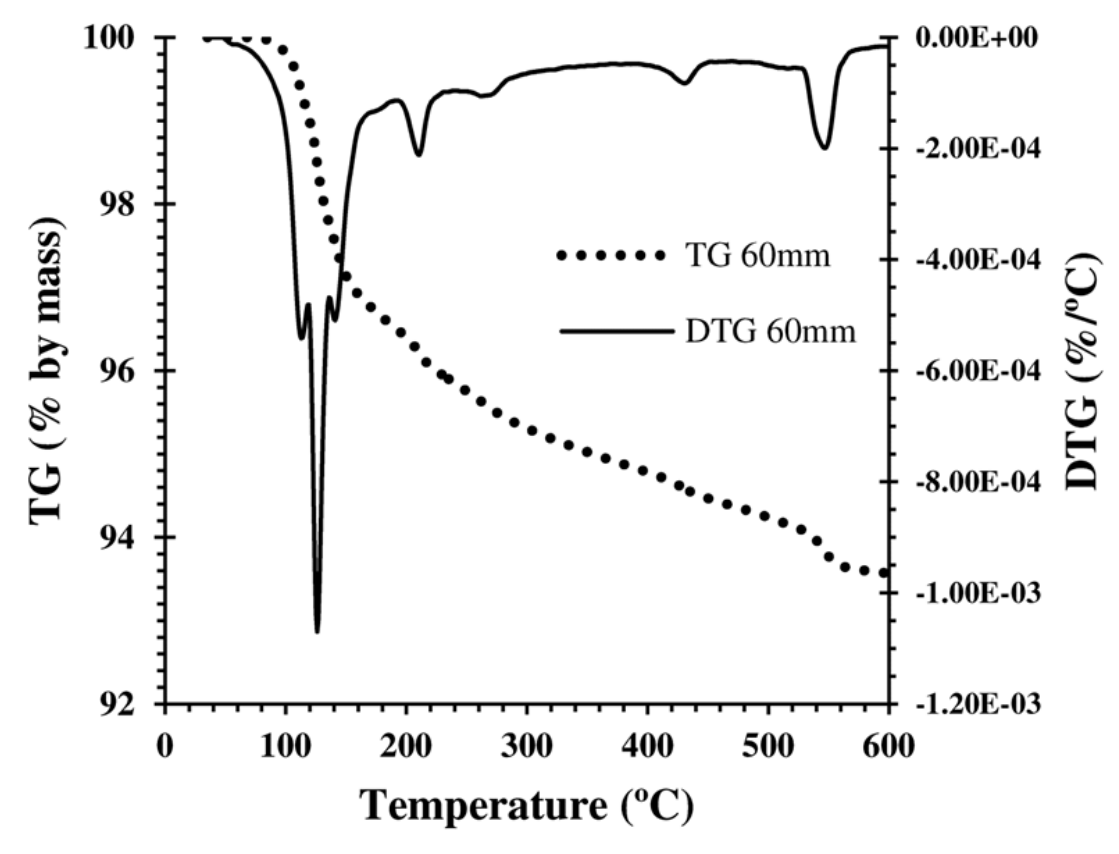

Fig 12. TG and DTG curves for non-carbonated concrete (sample taken $60 \mathrm{~mm}$ from the carbonated surface of the concrete). 
This last peak allowed us to calculate the amount of portlandite present in the sample [45], because the stoichiometry of the process is well known (this is not possible for the other decomposition steps). In this case, the percentage of portlandite was $1.32 \%$. This low value is due to the huge amount of fine aggregate in the sample and the type of cement (it has limestone filler L and slag S as mineral additions).

When concrete is exposed to carbonation, some chemical processes occur, and many of the hydrates in the Portland cement paste are transformed, mainly because in an acidic reagent, most of the calcium-containing hydrates react with $\mathrm{CO}_{2}$ and form calcium carbonate. Due to these reactions, the $\mathrm{pH}$ of the concrete is reduced to below 9 . These transformations can be easily observed by means of the changes produced in the thermogravimetric curve [46]. Thus, in Fig. 13, TG and DTG curves for a totally carbonated sample are depicted (sample taken $10 \mathrm{~mm}$ from carbonation surface of concrete). Most of the peaks disappeared; thus, C-S-H and Et were carbonated and most of the chemically combined water in these hydrates was removed in the carbonation process: in the non-carbonated sample, the mass loss in the $100-250{ }^{\circ} \mathrm{C}$ range was $4.30 \%$, whereas for the carbonated sample it was only $1.30 \%$. Additionally, the peak corresponding to the dehydration of $\mathrm{CH}$ disappeared after carbonation, due to the following chemical process:

$$
\mathrm{Ca}(\mathrm{OH})_{2}+\mathrm{CO}_{2} \Rightarrow \mathrm{CaCO}_{3}+\mathrm{H}_{2} \mathrm{O}
$$

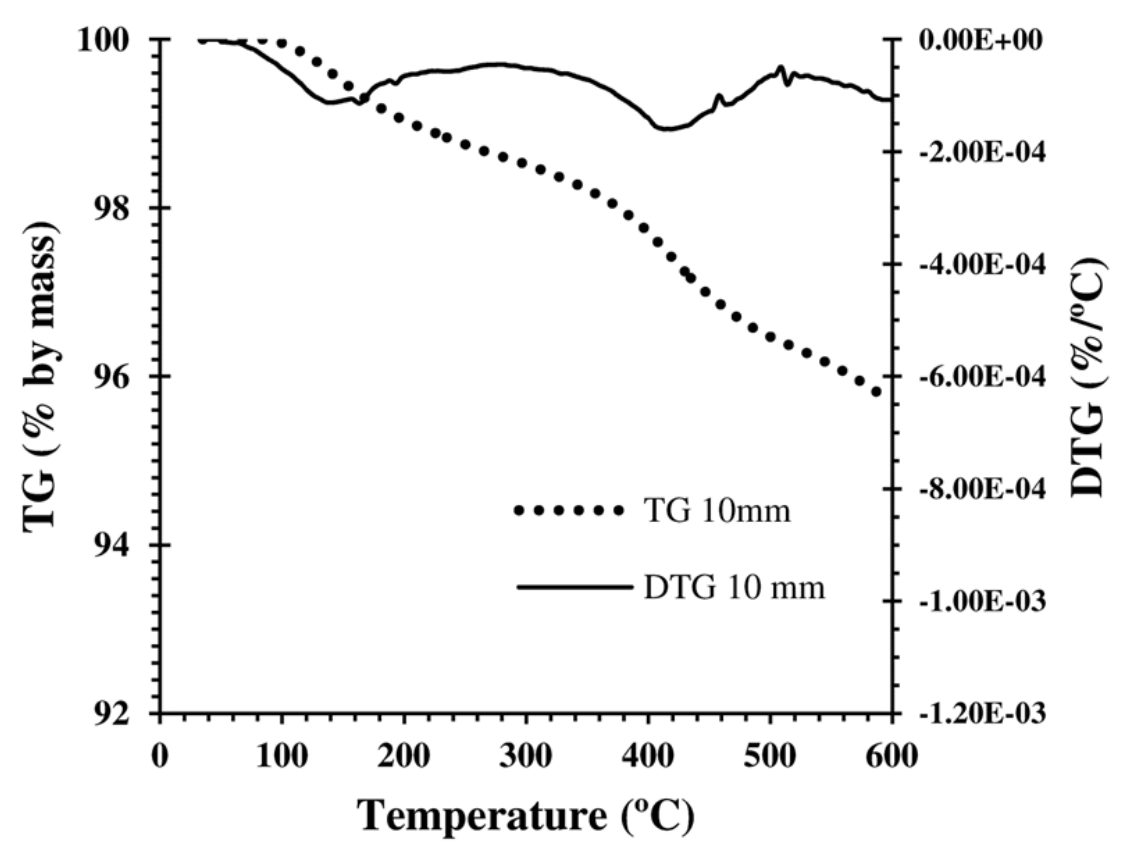

Fig 13. TG and DTG curves for a carbonated sample (sample taken $10 \mathrm{~mm}$ from the carbonated surface of the concrete). 
Fig. 14 shows the six DTG curves for the studied samples. It can be observed that there is a considerable change when the distance from the surface was $30 \mathrm{~mm}$. In this case, some hydrates decomposed in the 100$250^{\circ} \mathrm{C}$ range, indicating that some C-S-H and/or Et were not carbonated. Also, a small peak centred at $523^{\circ} \mathrm{C}$ is present, suggesting that the carbonation process was not completed. The percentage of portlandite at this depth was only $0.19 \%$, much lower than those found in the non-carbonated zone $(60 \mathrm{~mm})$.

For samples taken at $40 \mathrm{~mm}$ and $50 \mathrm{~mm}$ from the surface, the corresponding DTG curves were very similar to the curve observed for $60 \mathrm{~mm}$ depth. This behaviour means that the carbonation did not produce any changes because the $\mathrm{CO}_{2}$ did not reach this part of the concrete. One can observe that the most important changes occurred in the 10-40 mm zone, in accordance with the evolution observed in the DTG curves. The most important change related to the presence of portlandite was in the $20-30 \mathrm{~mm}$ zone, and this zone coincides with the carbonated front (associated with critical $\mathrm{pH}$ change) detected by the sensors.

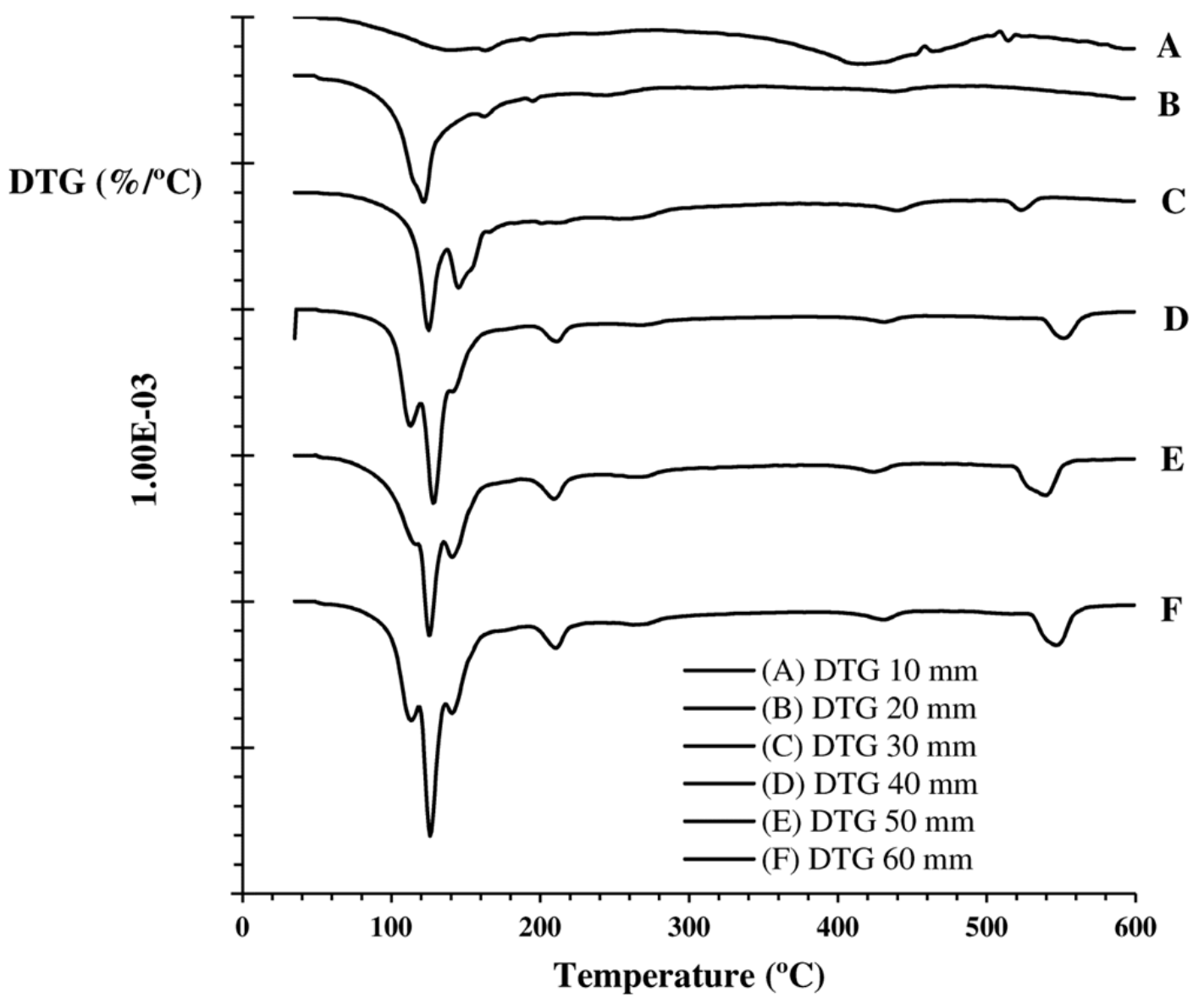

Fig. 14. DTG curves for selected samples at different distances from the carbonation surface of the concrete (Note: the $\mathrm{Y}$-axis is in a relative scale, in order to avoid the overlapping of the curves). 


\section{Conclusions}

In this study, screen-printed $\mathrm{Ag} / \mathrm{Ag}_{2} \mathrm{O}$ sensors were made with the purpose of performing $\mathrm{pH}$ measurements and assessing their utility in reinforced concrete structures. The following conclusions can be drawn from the results of this experimental work:

1. The electrical response of the sensors in solution was nearly Nernstian. Their sensitivity is $7.4 \%$ lower compared to the theoretical one, due to the presence of oxidizing agents in the resistive paste, which take more than one electron during the redox process. Titanium oxide and Ruthenium oxide sensors also display a quasi-Nerstian behaviour, their corresponding sensitivities are $15.8 \%$ and $22.1 \%$ lower than the theoretical sensitivity.

2. The $\mathrm{Ag} / \mathrm{Ag}_{2} \mathrm{O}$ sensors exhibit very good reproducibility and reversibility and a good response time according to its intended application to concrete monitoring (around 600 seconds).

3. An equation has been developed to model the $\mathrm{pH}$ value from the voltage values obtained by the $\mathrm{Ag} / \mathrm{Ag}_{2} \mathrm{O}$ and the temperature of the media.

4. The potentiometric interference constant for $\mathrm{Cl}^{-}$anion has been obtained, because it is a potential interferent to silver. Equation 6 allows the evaluation of the error induced by the presence of chlorides for any $\mathrm{pH}$ value.

5. The sensor array allows the progress of the carbonation front to be monitored in hardened concrete. Replicas located at different depths allow detecting the carbonation front as it reaches a new sensor, confirming the information obtained from the sensor system. This tool provides useful information to establish non-destructive diagnosis criteria for the evaluation of the durability of reinforced concrete structures.

\section{Acknowledgements}

The pre-doctoral scholarship was granted to Román Bataller Prats by the Research Staff Training Program, “Formación de Personal Investigador (FPI) 2012” from Universitat Politècnica de Valéncia and to José Enrique Ramón Zamora by the University Faculty Training Program, "Formación del Profesorado Universitario (FPU) 2013" from the Spanish Ministry of Science and Innovation. The financial support from 
the Spanish Government and the European FEDER funds MAT2012-38429-C04-04 is also gratefully acknowledged. ETSIE (UPV) by their support to the laboratory.

\section{References}

1. Richardson JA, Dawson JL. 4.31 - Economic Aspects of Corrosion, In Shreir's Corrosion. Oxford: Elsevier, 2010, 3040-3051

2. Bentur A, Diamond S, Berke NS. Steel corrosion in concrete: fundamentals and civil engineering practice. London: E\& FNSpon, 1997

3. Broomfield JP. Corrosion of steel in concrete: understanding, investigation and repair. London: E\& FNSpon, 1997

4. Huet B, L'Hostis V, Miserque F, Idrissi H. Electrochemical behavior of mild steel in concrete: Influence of $\mathrm{pH}$ and carbonate content of concrete pore solution, Electrochim. Acta 2005; 51 (1):172-180

5. Papadakis VG, Vayenas C.G, Fardis MN. Fundamental modeling and experimental investigation of concrete carbonation, ACI Mater. J, 1991; 88 (5): 363-373

6. Cheng-Feng $\mathrm{CH}$, Jing-Wen $\mathrm{CH}$, The experimental investigation of concrete carbonation depth, Cem. Concr. Res. 2006; 36 (9):1760-1767

7. RILEM Committee CPC-18, Measurement of hardened concrete carbonation depth, Mater. Struct. 1988; 18: $453-455$

8. Parrott LJ. A Review of Carbonation in Reinforced Concrete. Buckinghamshire: Cement and Concrete Association, Wexham Springs, 1987

9. Fukushima T, Yoshizaki Y, Tomosawa F, Takahashi K. Relationship between neutralization depth and concentration distribution of $\mathrm{CaCO}_{3}-\mathrm{Ca}(\mathrm{OH})_{2}$ in carbonated concrete. ACI Special Publication, 1998; 179: $347-363$

10. Villain G, Thiery M, Platret G. Measurement methods of carbonation profiles in concrete: Thermogravimetry, chemical analysis and gammadensimetry, Cem. Concr. Res. 2007; 37 (8): 1182-1192. 11. Papadakis VG, Fardis MN, Vayenas CG. Hydration and carbonation of pozzolanic cements. ACI Mater. J. 1992; 89 (2): 119-130 
12. Castillo A, Andrade C, Martinez I, Rebolledo N, Fernandez-Troyano L, Ayuso G, Cuervo J, Junquera J, Santana C, Delgado J. Evaluacion y monitorizacion de la durabilidad de las cubiertas del Hipodromo de la Zarzuela. Inf. Constr. 2011; 63 (524): 33-41

13. Andrade C, Martinez I, Castellote M, Zuloaga P. Some principles of service life calculation of reinforcements and in situ corrosion monitoring by sensors in the radioactive waste containers of El Cabril disposal (Spain) J. Nucl. Mater. 2006; 358: 82-95

14. Myrdal R. The electrochemistry and characteristics of embeddable reference electrodes for concrete. Cambridge, London: European Federation of Corrosion Publications, Woodhead Publishing Limited 2007 15. Hien Nguyen T, Thillainathan V, Chen S, Sun T, Kenneth T.V. Grattan, Taylor SE, Basheer M, Long AE. Fluorescence based fibre optic $\mathrm{pH}$ sensor for the $\mathrm{pH} 10-13$ range suitable for corrosion monitoring in concrete structures, Sens. Actuators B 2014; 191: 498-507

16. Blumentritt M, Melhorn K, Flachsbarth J, Kroener M, Kowalsky W, Johannes HH. A novel fabrication method of fiber-optical planar transmission sensors for monitoring $\mathrm{pH}$ in concrete structures, Sens. Actuators B 2008; $131(2): 504-508$

17. Shi-Gang D, Chang-Jian L, Rong-Gang H, Lan-Qiang L, Rong-Gui D. Effective monitoring of corrosion in reinforcing steel in concrete constructions by a multifunctional sensor, Electrochim. Acta. 2011; 56 (4): $1881-1888$

18. Yu H, Caseres L. An embedded multi-parameter corrosion sensor for reinforced concrete structures, Mater. Corros. 2012; 63 (11): 1011-1016

19. Du RG, Hu RG, Huang RS, Lin C J. In situ measurement of Cl-concentrations and $\mathrm{pH}$ at the reinforcing steel/concrete interface by combination sensors. Anal. Chem. 2006; 78(9): 3179-3185

20. Castro P, Sagues A.A, Moreno EI, Maldonado L, Genesca J. Characterization of Activated Titanium Solid Reference Electrodes for Corrosion Testing of Steel in Concrete. Corrosion 1996; 52 (8): 609-617 21. Jabir SAA, Gupta NK. Thick-Film Ceramic Strain Sensors for Structural Health Monitoring IEEE Transactions on Instrumentation and Measurement 2011; 60 (11): 3669-3676

22. Jabir SAA, Gupta NK. Condition monitoring of the strength and stability of civil structures using thick film ceramic sensors. Measurement 2013; 46 (7): 2223-2231

23. Fog A, Buck RP. Electronic semiconducting oxides as pH sensors, Sens. Actuators 1984, 5 (2): 137-146 
24. Pasztor K, Sekiguchi A, Shimo N, Kitamura N, Masuhara H, Electrochemically-deposited $\mathrm{RuO}_{2}$ films as pH sensors, Sens. Actuators B 1993; 14 (1-3): 561-562

25. McMurray HN, Douglas P, Abbot D. Novel thick-film pH sensors based on ruthenium dioxide-glass composites. Sens. Actuators B 1995; 28 (1): 9-15

26. Koncki R, Mascini M. Screen-printed ruthenium dioxide electrodes for $\mathrm{pH}$ measurements. Anal. Chim. Acta, 1997; 351 (1-3):143-149

27. Mihell, JA, Atkinson, JK. Planar thick-film $\mathrm{pH}$ electrodes based on ruthenium dioxide hydrate. Sensors and Actuators B, 1998; 48 (1 -3): 505-511

28. Atkinson, JK, Cranny AWJ, Glasspool WV, Mihell, JA. Investigation of the performance characteristics and operational lifetimes of multi-element thick film sensor arrays used in the determination of water quality parameters. Sens. Actuators B 1999; 54 (3): 215-231

29. Martínez-Mañez R, Soto J, García-Breijo E, Gil L, Ibáñez J, Gadea E. A multisensor in thick-film technology for water quality control. Sens. Actuators A 2005; 120 (2): 589-595

30. García-Breijo E. Diseño de un sistema multisensor en tecnología thick-film; fabricación, caracterización y estudio de su aplicabilidad a la medida de parámetros físico-químicos. PhD thesis. Valencia. Universidad Politécnica de Valencia, 2004

31. Commission on Analytical Nomenclature, Pure \& Applied Chemistry. 48 1975, 129-135

32. Soto J, Labrador RH, Marcos MD, Martínez-Máñez R, Coll C, Garcia-Breijo E, Gil L. Introduction of a model for describing the redox potential in faradic electrodes. J. Electroanal. Chem. 2006; 594(2): 96-104

33. Labrador RH, Soto J, Martínez-Máñez R, Coll C, Benito A, Ibáñez J, Garcia-Breijo E, Gil L. An electrochemical characterization of thick-film electrodes based on $\mathrm{RuO}_{2}$ containing resistives pastes. J. Electroanal. Chem. 2007; 611 (1-2): 175-180

34. Gandía-Romero JM, Bataller R,Monzón P, Campos I, García-Breijo E, Valcuende M, Soto J. Characterization of embeddable potentiometric thick-film sensors for monitoring chloride penetration in concrete. Sensors and Actuators B 2016; 222:407-418

35. Sisomphon K, Franke L. Carbonation rates of concretes containing high volume of pozzolanic materials. Cement and Concrete Research 2006; 37(8):1647-1653 
36. Alexander MG, Mackechnie JR, Yam W. Carbonation of concrete bridge structures in three South African localities. Cement and Concrete Composites 2007; 29(10):750-759

37. Wierig HJ. Longtime studies on the carbonation of concrete under normal outdoor exposure. Proceedings of the RILEM Seminar on the durability of concrete structures under normal outdoor exposure. Hannover, 1984

38. Khunthongkeaw J, Tangtermsirikul S, Leelawat T. A study on carbonation depth prediction for fly ash concrete. Construction and building materials 2006; 20(9):744-753

39. Comité Euro-international du Béton (CEB). Durable concrete structures: design guide. Thomas Telford publication ltd, 1992

40. Thiery M, Villain G, Dangla P, Platret G. Investigation of the carbonation front shape on cementitious materials: Effects of the chemical kinetics. Cem. Concr. Res. 2007; 37: 1047-1058

41. Verbeck GJ. Carbonation of hydrated Portland cement, ASTM Spec. Tech. Publ., 1958; 205:17-36

42. Galan I, Andrade $\mathrm{C}$, Castellote $\mathrm{M}$. Natural and accelerated $\mathrm{CO}_{2}$ binding kinetics in cement paste at different relative humidities. Cem. Concr. Res. 2013; 49:21-28

43. Hewlett PC, Lea's Chemistry of Cement and Concrete (Fourth Edition). Elsevier 2003

44. Ramachandran VS, Paroli RM, Beaudoin JJ, Delgado AH. Handbook of Thermal Analysis of Construction Materials. Noyes Publications 2002

45. Soriano L, Monzó J, Bonilla M, Tashima MM, Payá J, Borrachero MV. Effect of pozzolans on the hydration process of Portland cement cured at low temperatures. Cem Concr Compos 2013; 42: 41-48 46. Zornoza E, Payá J, Monzó J, Borrachero MV, Garcés P. The carbonation of OPC mortars partially substituted with spent fluid catalytic catalyst (FC3R) and its influence on their mechanical properties. Construc Build Mat 2009; 23; 1323-1328 


\section{Figure captions}

Fig. 1. A) Conductive layer; B) Active layer; C) Protective layer; D) Substrate dimensions; E) Real image Fig. 2. Sensor location scheme (distances in $\mathrm{mm}$ ).

Fig. 3. Data acquisition system.

Fig. 4. Sensor conditioning. Converging the evolution of the obtained signal with three different sensors made of silver oxide against time.

Fig. 5. Graphs showing potential against $\mathrm{pH}$ belonging to the three types of pastes used at $25^{\circ} \mathrm{C}$.

Fig. 6. Experimental data obtained with a single sensor and corresponding fit.

Fig. 7. Reversibility test for Type 1 sensors (four sensors). Potential (SCE) vs time (s). Stage 1: $\mathrm{pH}$ 12.6;

Stage 2: pH 11.14; Stage 3: pH 12.6; Stage 4: $\mathrm{pH} 9.6$; Stage 5: $\mathrm{pH}$ 12.6; Stage 6: $\mathrm{pH}$ 8.37; Stage 7: pH 12.6

Fig. 8. Sensor calibration lines for Type 1 sensors in solutions at temperatures of 10,25 and $40^{\circ} \mathrm{C}$.

Fig. 9. Potential variation against $\log \left[\mathrm{Cl}^{-}\right]$in a $\mathrm{pH} 9.6$ solution

Fig. 10. Variation of $\mathrm{pH}$ and potential over time for 5 sensors in a concrete test specimen subjected to accelerated carbonation testing.

Fig. 11. Phenolphthalein test.

Fig 12. TG and DTG curves for non-carbonated concrete (sample taken $60 \mathrm{~mm}$ from the carbonated surface of the concrete).

Fig 13. TG and DTG curves for a carbonated sample (sample taken $10 \mathrm{~mm}$ from the carbonated surface of the concrete).

Fig 14. DTG curves for selected samples at different distances from the carbonation surface of the concrete (Note: the $\mathrm{Y}$-axis is in a relative scale, in order to avoid the overlapping of the curves). 


\section{Tables}

Table 1. Table 1. EDS analysis results from the three analysed pastes.

Table 2. Mix proportions and mechanical properties of concrete

Table 3. Sensitivity and average standard potential at $25^{\circ} \mathrm{C}$ (vs SCE)

Table 4. Number of exchanged electrons for each paste.

Table 5. Speed constants and mean response times obtained based on $\mathrm{pH}$ variation.

Table 6. Potential (SCE) of the sensors at the end of the seven test stages

Table 7. Potential response $(\mathrm{mV})$ against temperature

Table 8. Sensitivity and standard average potential variation with respect to temperature for Type 1 sensors. 